\title{
Detection of p53 gene mutation by using a novel biosensor based on localized surface plasmon resonance
}

\author{
R. Q. DUAN ${ }^{1}$, J. L. YUAN ${ }^{1}$, H. YANG ${ }^{2}$, X. G. LUO ${ }^{2}$, M. R. XI $I^{1, *}$ \\ ${ }^{1}$ Department of Gynecology \& Obstetrics, West China Second University Hospital, Sichuan University, Chengdu 610041, China; ${ }^{2}$ State Key Labo- \\ ratory of Optical Technologies for Microfabrication, Institute of Optics and Electronics, Chinese Academy of Science, Chengdu 610209, China
}

*Correspondence: qmrjzz@126.com

Received December 17, 2011 / Accepted January 5, 2012

\begin{abstract}
Few studies to date have reported on the development and application of a nanobiosensor based on localized surface plasmon resonance (LSPR) for detecting gene mutations. This study aimed to develop a novel LSPR biosensor used for detecting p53 mutation. Nanosphere lithography was used to fabricate the silver nanoparticles. The DNA probe was designed to recognize the target sequence and immobilized on the chip surface by a covalent-coupling method using amine-group ligands. Synthetic oligonucleotides or PCR products were amplified from genomic DNA taken from blood samples and hybridized with the immobilized probe. Wild-type and mutant p53 was detected by measuring shifts in peak of LSPR extinction spectra. The low detection limit of the sensor for target sequence was $10 \mathrm{nM}$, and detection occurred over a wide dynamic range (10 $\mathrm{nM}-10 \mu \mathrm{M})$. Importantly, the differences in measuring signal between wild-type and mismatched p53 DNA was significant, allowing for this sensor to effectively discriminate against single base mutations. In conclusion, we developed a biosensor with potential as a rapid, label-free, sensitive, and low-cost method for detecting p53 mutation. Our results suggest that such an LSPR-based biosensor provides an attractive alternative for clinical detection of genetic mutation.
\end{abstract}

Key words: biosensor, localized surface plasmon resonance, gene mutation

Recently, noble metal nanoparticles have attracted much research attention for their potential application in biosensors, due to the remarkable optical properties of localized surface plasmon resonance (LSPR) [1-4]. Generally, LSPR arises in noble metal nanoparticles, especially $\mathrm{Au}$ and $\mathrm{Ag}$, when the incident photon frequency resonates with collective oscillations of free electrons [5]. Meanwhile, nanoparticles present strong localized surface plasmon absorption in this situation, which can be monitored in the UV-visible region [6]. The LSPR absorption and extinction spectra are known to strongly depend on the composition, size, shape, orientation, and local dielectric environment of nanoparticles [7]. In particular, the peak wavelength of the LSPR extinction maximum spectrum $(\lambda \max )$ is highly sensitive to dielectric changes in the environment around the nanoparticles; and even small changes in the local refractive index, caused by biomolecular interactions, can result in an obvious shift in the LSPR $\lambda \max$ [5]. This optical property enables noble metal nanoparticles to serve as extremely sensitive biosensors.

Using LSPR biosensors, local refractive index changes induced by biospecific interactions occurring at the surface can be directly converted into peak wavelength shifts, which is measurable by simple and inexpensive LSPR spectrometer instruments [7]. Thus, LSPR biosensors provide an effective platform for monitoring biomolecular interactions in real time, upon binding of target molecules, the LSPR peak wavelength shifts towards the longer wavelength region. By this way, the LSPR biosensor can be successfully used for biomolecular detection [8-12]. However, to date, LSPR biosensors have not been applied to the detection of gene mutations.

p53 is a key tumor suppressor gene that plays crucial roles in the induction of cell cycle arrest and apoptosis in response to DNA damage $[13,14]$. However, p53 mutations, induced by replication errors and exposure to environmental carcinogens, disrupt its normal function and impair genomic stability. p53 mutation has been detected in most types of human cancers, and is regarded as the most common genetic alteration associated with tumorigenesis [13-17]. Furthermore, p53 mutations, especially those occurring in its L2 and L3 zinc binding domains, are strongly associated with radiotherapy- and chemotherapyresistance and poor prognosis for some of the most frequently 
diagnosed cancers [18-20]. Therefore, detection of p53 mutation has become increasingly important since it may guide development of effective individualized therapy, which is expected to improve the prognosis of tumor patients.

At present, a variety of methods are used to detect p53 mutations, including direct DNA sequencing, denaturing gradient gel electrophoresis, denaturing high-performance liquid chromatography (HPLC), and single-strand conformation polymorphism electrophoretic separation [21]. However, most of these methods require a relatively long assay time, involving complex steps and a labeling procedure. Additionally, some are less sensitive and require expensive instruments or highly-skilled operators [22, 23]. Among them, direct DNA sequencing is considered as the gold standard for detecting p53 mutation, but it is a time-consuming and expensive technique that is not feasible for all laboratories. Other methods, such as restriction fragment length polymorphism and tetra primer amplification refractory mutation system PCR, require electrophoresis, which is not only time-consuming but also uses toxic reagents [24]. These various disadvantages limit the widespread clinical application of these methods. Therefore, it is urgent to develop a new rapid, label-free, simple, inexpensive, and sensitive technique to detect p53 mutation.

To overcome the disadvantages of the current methods, we developed a novel LSPR nanobiosensor for detecting p53 mutation in the present study. The L2 zinc binding domain of p53 was chosen as the target sequence, based on its character as a mutational hotspot and its structural importance. Both synthetic oligonucleotides and PCR products amplified from patient blood samples were detected using this sensor. Our results suggest that the newly-developed LSPR nanobiosensor has potential for clinical applications in detecting gene mutations.

\section{Materials and Methods}

Materials. An amine-terminated DNA probe corresponding to the $\mathrm{L} 2$ zinc binding domain in human $\mathrm{p} 53\left(3^{\prime}-\mathrm{H}_{2} \mathrm{~N}-\left(\mathrm{CH}_{2}\right)_{6}-\right.$ CAACACTCCGCGACGGGGGTGGTAC-5'), a normal L2 zinc binding domain sequence (5'-GTTGTGAGGCGCTGCCCCCACCATG-3'), a corresponding one-base mismatch sequence ( $\mathrm{G} \rightarrow \mathrm{A}$ at codon $175 ; 5^{\prime}$-GTTGTGAGGCACTGCCCCCACCATG-3'), and a non-complementary sequence (5'-GCGTCCGCGCCATGGCCATCTACAA-3') were synthesized and HPLC-purified by TaKaRa (Dalian, China). The 11-mercaptoundecanoic acid (MUA), N-hydroxysuccinimide (NHS), and 1-ethyl-3-(3-dimethylamino-propyl) carbodiimide hydrochloride (EDC) were purchased from Sigma-Aldrich (St. Louis, MO, USA). Polystyrene and glass nanospheres in suspension were obtained from Waters Co. (Milford, MA, USA). Quartz glass substrates were obtained from Juke Co. (Chengdu, China). Ag wire was purchased from Jubo Co. (Beijing, China). Ultrapure water $(18.3 \mathrm{MV} / \mathrm{cm}$ ) was from Millipore Co. (Boston, MA, USA). All chemicals were of reagent grade.

The immobilization solution was composed of $0.1 \mathrm{M} \mathrm{NaCl}$ in phosphate buffer solution $(25 \mathrm{mM}$ sodium phosphate,
$\mathrm{pH}$ 8.4). The hybridization buffer was composed of $1 \mathrm{M} \mathrm{NaCl}$ in TE buffer solution (10 mM Tris, $1 \mathrm{mM}$ EDTA, $\mathrm{pH} \sim 7.6$ ).

Construction of the LSPR biosensor. The integrated LSPR sensor was built on-site, as described previously [8]. Briefly, nanosphere lithography (NSL) was used to fabricate the triangular-shaped silver nanoparticles. Before and after each incubation step, the peak wavelength $(\lambda \max )$ excited by $\mathrm{Ag}$ nanoparticles was measured and recorded by a UV-vis spectrometer (Model 9055; Sciencetech Corp., Ottawa, Canada). The extinction spectra were directly obtained using Spectra Suite software (Ocean Optics Corp., Dunedin, FL, USA).

White light emerging from the optical fiber bundle was incident to the nanochip surface. Coupled with the optical detection probe, the reflected light was analyzed by using the UV-vis spectrometer. The maximum extinction of each spectrum was determined based on its first derivative. All absorbance spectra were taken in the range of $400-800 \mathrm{~nm}$ in air at room temperature. The relative wavelength shift, $\Delta \lambda$ max, was used to monitor the binding of target DNA through hybridization. A shift towards the longer wavelength region was referred to as a red-shift and indicated as (+); whereas, a shift towards the shorter wavelength region was referred to as a blue-shift and indicated as (-). The resolution of our system was $0.5 \mathrm{~nm}$, which indicated that the bisoensor could detect the analyte at the nanoparticles-solution interface when the $\Delta \lambda \max$ was more than $+0.5 \mathrm{~nm}$.

Immobilization of the probes on the nanoparticle layer surface. To form a self-assembled monolayer (SAM) on the slice surface, the silver nanochip was immersed in $1 \mathrm{mM}$ MUA solution (in ethanol) for $10 \mathrm{~h}$ at room temperature, then washed with pure ethanol and dried at room temperature. Subsequently, the slice was incubated in $200 \mathrm{mM} \mathrm{EDC} / 50 \mathrm{mM}$ NHS solution for $2 \mathrm{~h}$ at room temperature to activate the carboxyl group of the SAM. Next, the slice was washed thoroughly by ultrapure water and dried. The amine-terminated DNA probe was dissolved in immobilization solution at various concentrations of $1,10,50$, or $100 \mu \mathrm{M}$. The probes were dropped onto the modified surface in $10 \mu \mathrm{L}$ aliquots, and the slice was incubated in a humidified chamber for $8 \mathrm{~h}$. Finally, the sensor surface was rinsed thoroughly with ultrapure water and dried at room temperature. The procedures for immobilizing the probes on the chip surface are outlined in Figure 1.

PCR. Genomic DNA was extracted from $200 \mathrm{~mL}$ EDTA anticoagulated peripheral blood samples by using a commercial DNA isolation kit (Bioteke, Beijing, China) and following the manufacturer's instructions. Blood samples had been obtained from 26 patients who signed informed consent under an Institutional Review Board approved protocol. A $186 \mathrm{bp}$ DNA fragment containing the target sequence was PCR amplified by using the sense primer ( $5^{\prime}$-CCTGCCCTCAACAAGATGTTT-3 $\left.{ }^{\prime}\right)$ and the anti-sense primer (5'-CTGCTCACCATCGCTATCTG-3') (TaKaRa). The thermal cycling conditions were as follows: $94^{\circ} \mathrm{C}$ for $4 \mathrm{~min} ; 35 \mathrm{cycles}$ of $94^{\circ} \mathrm{C}$ for $30 \mathrm{sec}, 57^{\circ} \mathrm{C}$ for $30 \mathrm{sec}$, and $72^{\circ} \mathrm{C}$ for $30 \mathrm{sec}$; and, $72^{\circ} \mathrm{C}$ for $10 \mathrm{~min}$. All PCR experiments were conducted with a C1000 Thermal Cycler instrument (Bio-Rad, Hercules, CA, USA). PCR products containing normal (wild- 


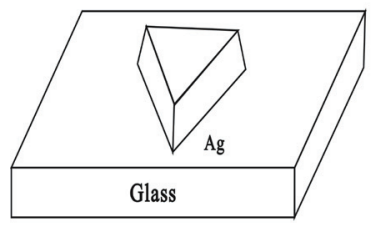

A

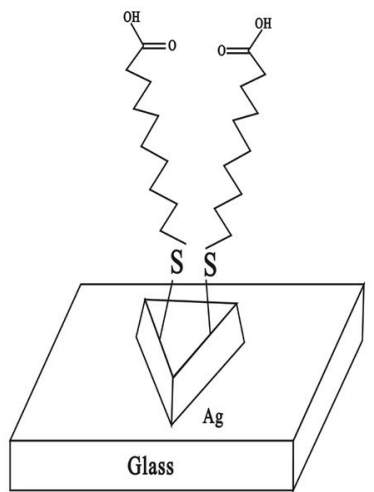

B
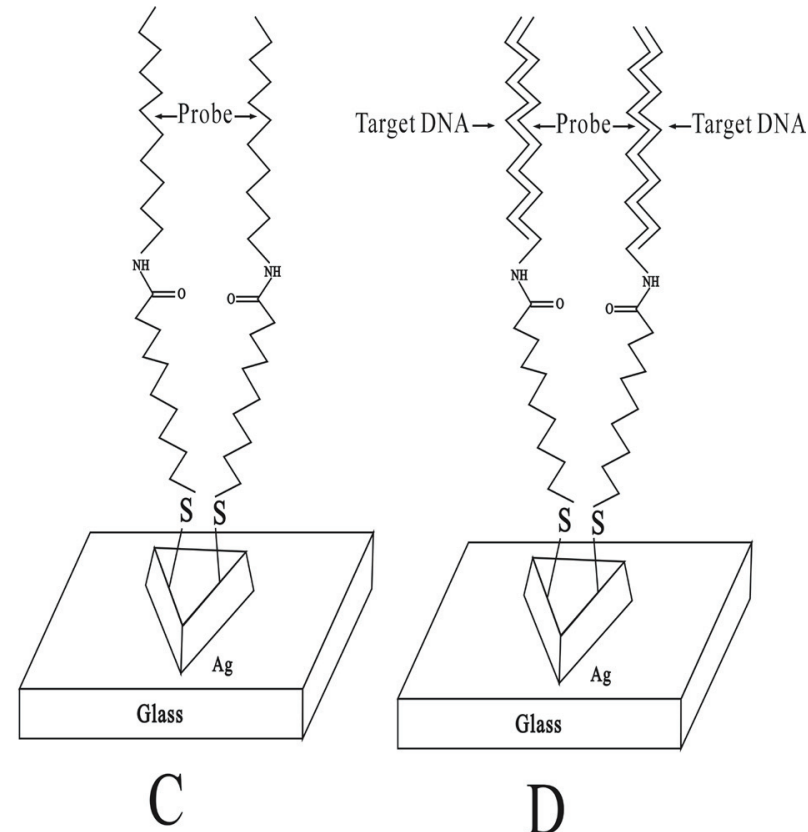

Figure 1. Design of an LSPR nanobiosensor for detecting p53 gene mutations. (A) Triangular Ag nanoparticles were fabricated on a glass substrate using NSL. (B) The nanoparticles were modified with MUA to form a SAM. (C) Amine-terminated DNA probes were immobilized on the MUA-coated nanoparticles with EDC/NHS activation. (D) Target DNA was hybridized with the immobilized probe.

type) or mutated sequence ( $\mathrm{G} \rightarrow \mathrm{A}$ at codon 175$)$ were verified by direct DNA sequencing (3730XL sequencer; Applied Biosystems, Inc., Carlsbad, CA, USA). The mutated PCR product was amplified from genomic DNA of an ovarian cancer patient. Finally, PCR products were denatured by incubation at $94^{\circ} \mathrm{C}$ for $6 \mathrm{~min}$, followed by incubation on ice for $3 \mathrm{~min}$, after which the single-strand products were hybridized with the probes on the biosensor.

Detection of DNA hybridization using the LSPR biosensor. Synthetic oligonucleotides and PCR products diluted in hybridization buffer were hybridized with the immobilized probes on the biosensor surface by incubating at $37^{\circ} \mathrm{C}$ for $2 \mathrm{~h}$. A negative control was made by adding a blank solution that contained all the PCR reagents and no DNA template, and incubating the mixture under the same conditions described above. Subsequently, the chips were rinsed with hybridization buffer and ultrapure water, and dried at room temperature. Ultimately, the changes in LSPR absorption spectra caused by DNA hybridization were observed.

\section{Results}

Efficient immobilization of the probes onto the nanochip surface. The immobilization process of the probes onto the silver nanochip is demonstrated in Figure 1. First, the silver nanochip was modified with a self-assembled monolayer of MUA. Upon EDC/NHS activation, the amine-terminated probe was covalently attached to the carboxylic acid groups of MUA. LSPR spectroscopy was used to monitor the process of probe immobilization. According to the Mie theory, binding of an organic molecule to a nanochip can induce an increase in the local refractive index, and result in a red-shift of the LSPR wavelength peak [3]. Thus, the wavelength shift $(\Delta \lambda \max )$ could act as a reliable indicator of molecular binding onto the surface of nanoparticles. In the present study, after the silver nanochips were incubated on SAM for $10 \mathrm{~h}$, a representative LSPR wavelength was observed to shift to $+23.53 \mathrm{~nm}$, achieving a $\lambda$ max of $601.97 \mathrm{~nm}$ (Fig. 2.B). These chips were then incubated with the probes for $8 \mathrm{~h}$, and the LSPR extinction peak was measured and found to be $611.13 \mathrm{~nm}$ and red-shifted by $9.16 \mathrm{~nm}$ (Fig. 2.C). The $50 \mu \mathrm{M}$ of probe was determined to be an optimal concentration when the maximum peak shift appeared. Taken together, these results demonstrated that the probes were successfully immobilized on the SAM functionalized nanoparticles.

Detection of synthetic oligonucleotides with the LSPR biosensor. LSPR spectra were measured after the chips were incubated with various target sequences. The results showed that the extinction wavelength maximum shifted $+20.24 \mathrm{~nm}$ with complementary sequence at $10 \mu \mathrm{M}$ (Fig. 2.D), $+15.05 \mathrm{~nm}$ at $5 \mu \mathrm{M},+12.74 \mathrm{~nm}$ at $1 \mu \mathrm{M},+5.33 \mathrm{~nm}$ at $100 \mathrm{nM}$, and +3.82 $\mathrm{nm}$ at $10 \mathrm{nM}$. However, when the assay was repeated with the one-base mismatch sequence, the $\lambda$ max only shifted +9.81 $\mathrm{nm}$ at $10 \mu \mathrm{M},+4.44 \mathrm{~nm}$ at $5 \mu \mathrm{M},+3.44 \mathrm{~nm}$ at $1 \mu \mathrm{M},+2.05 \mathrm{~nm}$ at $100 \mathrm{nM}$, and $+1.64 \mathrm{~nm}$ at $10 \mathrm{nM}$. No significant changes or blue-shift were observed in the spectra, when the concentration of target sequence was decreased to $5 \mathrm{nM}$ or increased to $15 \mu \mathrm{M}$. There was, however, a significant decrease in the LSPR $\lambda \max$ shift with one-base mismatch sequence, as compared 


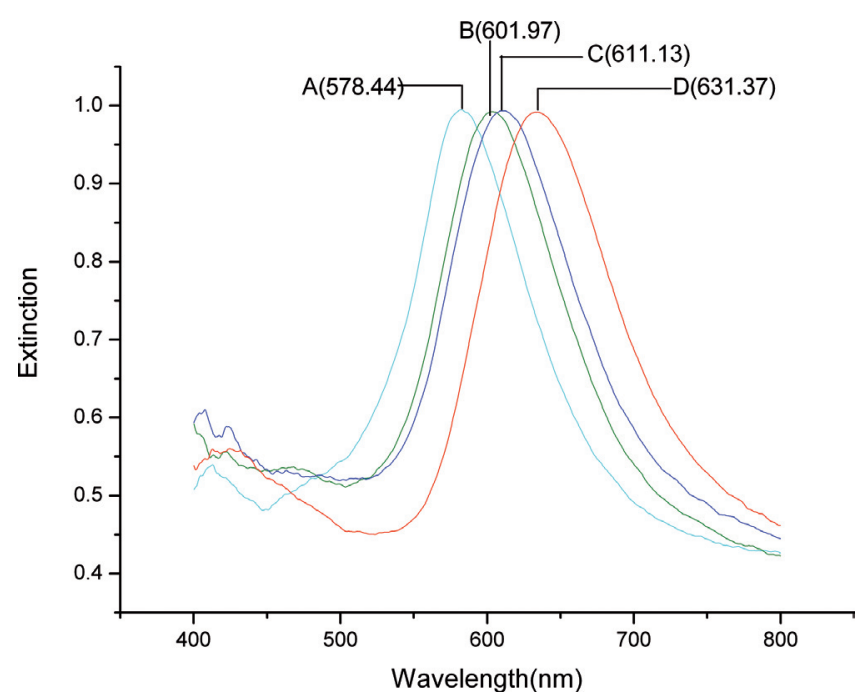

Figure 2. Detection of synthetic oligonucleotides by the LSPR biosensor. (A) Ag nanoparticles without modification. (B) MUA (1 mM). (C) Probe $(50 \mu M)$. (D) Complementary sequence $(10 \mu \mathrm{M})$. All spectra were observed in air.

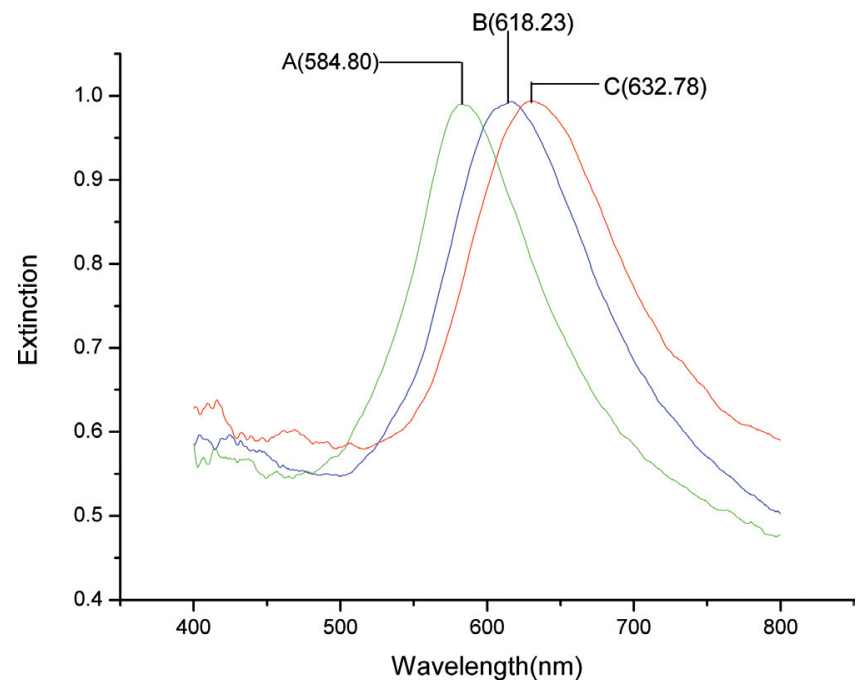

Figure 4. Detection of wt p53 PCR products by the LSPR biosensor. (A) Ag nanoparticles without modification. (B) Probe. (C) Wt PCR product $(1 \mu \mathrm{M})$. All spectra were observed in air.

to that achieved with complementary sequence at the same concentration (Fig. 3). In addition, when an adequate amount of non-complementary sequence $(10 \mu \mathrm{M})$ was introduced to the LSPR biosensor, no significant shift in the LSPR $\lambda$ max was observed. As expected, no additional DNA resulting from non-specific binding was found on the sensor chip.

Detection of $\mathrm{p} 53 \mathrm{PCR}$ products with the LSPR biosensor. Using the newly-developed biosensor, the diluted PCR products containing target sequence were also detected. The p53 PCR products were respectively diluted up to $1 \mu \mathrm{M}, 100 \mathrm{nM}$, and 10 $\mathrm{nM}$ in hybridization buffer. After PCR product containing the

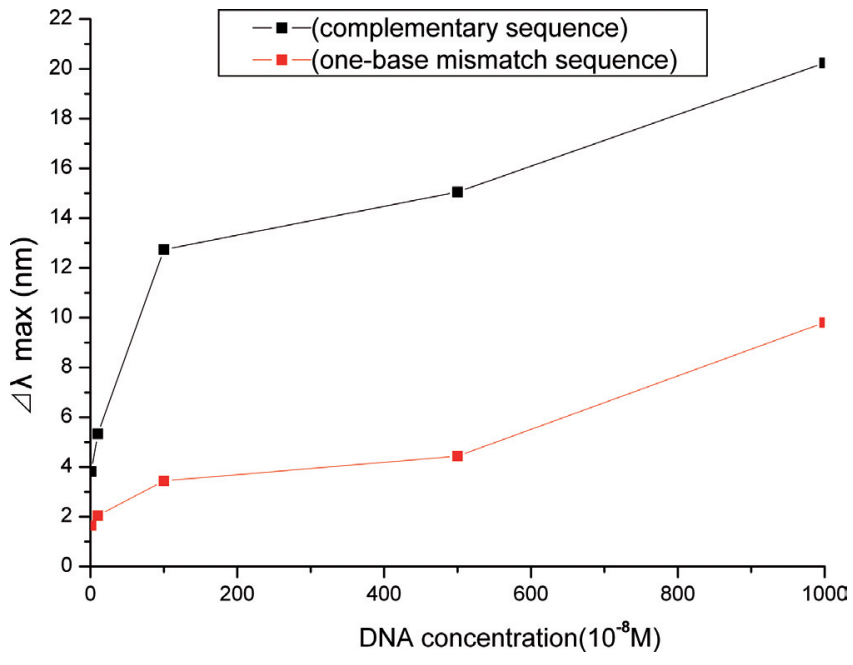

Figure 3. Linear plot of LSPR wavelength shift vs. p53 sequence concentration.

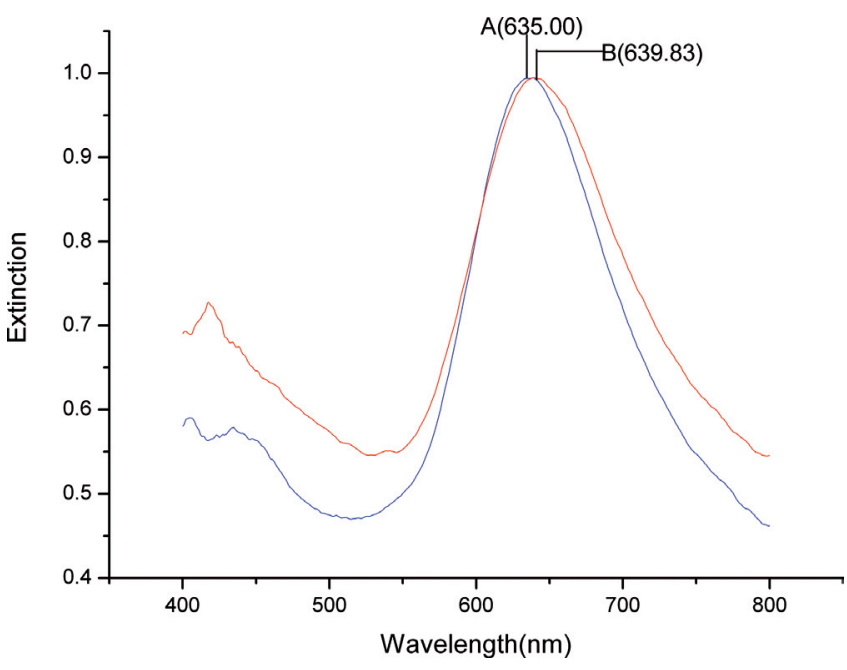

Figure 5. Detection of mutant p53 PCR products by the LSPR biosensor. (A) Probe. (B) Mutant $P C R$ product $(G \rightarrow A$ at codon 175$)(1 \mu \mathrm{M})$. All spectra were observed in air.

wild-type (wt) sequence was introduced to the LSPR biosensor, the representative LSPR $\lambda$ max shifted $+14.55 \mathrm{~nm}$ at $1 \mu \mathrm{M}$ (Fig.4), $+8.23 \mathrm{~nm}$ at $100 \mathrm{nM}$, and $+4.74 \mathrm{~nm}$ at $10 \mathrm{nM}$. However, under the same experimental conditions, with mutated PCR product ( $\mathrm{G} \rightarrow \mathrm{A}$ at codon 175 ), the representative $\lambda$ max only shifted $+4.83 \mathrm{~nm}$ at $1 \mu \mathrm{M}$ (Fig. 5), $+2.83 \mathrm{~nm}$ at $100 \mathrm{nM}$, and $+1.97 \mathrm{~nm}$ at $10 \mathrm{nM}$. The difference in binding signal $(\Delta \lambda \max )$ between wt and mutant $\mathrm{p} 53$ PCR products was significant, suggesting that this sensor allowed discrimination between wt and mutated PCR products by comparing the shifts in LSPR $\lambda$ max. The $\Delta \lambda \max$ of mutated PCR products was obviously less than that measured 
with same concentration of wt PCR products. Moreover, our results for $\mathrm{p} 53 \mathrm{PCR}$ products detection were in highly agreement with the data obtained with direct DNA sequencing (3730XL sequencer; Applied Biosystems, Inc., Carlsbad, CA, USA), indicating the good accuracy of this detection method. The total process of testing took only $2 \mathrm{~h}$.

Meanwhile, the blank PCR solution was detected as a negative control. The results demonstrated that the absorbance strength change was very small, $\Delta \lambda \max$ was only $+0.41 \mathrm{~nm}$. This small spectrum shift was within the range of experimental error $(\Delta \lambda \max =0.54 \pm 0.12 \mathrm{~nm}, n=3$ trials), indicating that nonspecific binding could be effectively suppressed with stringent washing of the biosensor surface. Meanwhile, the reproducibility of the biosensor was estimated by detecting the same concentration $(1 \mu \mathrm{M})$ of wt PCR product with five different chips on which the same probe had been immobilized. The average binding signal $(\Delta \lambda \max )$ obtained with $1 \mu \mathrm{M}$ wt PCR product was $13.94 \mathrm{~nm}$ with $\mathrm{SD}=1.40 \mathrm{~nm}$ and $\mathrm{CV} \%=10.0 \%$, signifying good reproducibility and reliability of this sensor.

\section{Discussion}

It is well-known that hybridization of a suitable oligonucleotide probe will facilitate detection of a target DNA sequence via complementary base pairing [25]. In this study, we used the designed oligonucleotide probe as the biorecognition layer of the sensor, which could bind to complementary sequence with high affinity and sequence specificity. The results demonstrated that hybridization between the immobilized probe and target DNA in solution could be quickly converted into a measurable signal ( $\Delta \lambda \max )$. This LSPR biosensor was found to be extremely sensitive to dielectric environmental changes induced by binding of target DNA. Under optimal conditions, the low detection limit of our sensor could achieve detection of $10 \mathrm{nM}$ target sequence, which could be performed at a wide dynamic range of $10 \mathrm{nM}$ to $10 \mu \mathrm{M}$. Moreover, we found that this sensor could effectively discriminate single base mutations occurring in p53 through comparing the difference in $\Delta \lambda$ max between wt and mutant DNA, by using either synthetic oligonucleotides or PCR products amplified from genomic DNA of blood samples.

The remarkable difference observed in $\Delta \lambda$ max between wt and mutant p53 DNA could be attributed to the mismatched sequence, which influenced base pairing and binding of target DNA onto the LSPR biosensor. According to Mie's theory, the nanochip's change in local refractive index decreased, and consequently the corresponding LSPR $\lambda$ max shift was reduced. To verify that the response observed on the LSPR sensor was due to specific binding of target DNA, we analyzed the parallel non-specific binding and the results demonstrated that there was no additional non-specific DNA bound to the sensor chip. The very small shift observed with the blank PCR solution could be attributed to slight spectrometer noise. These results clearly demonstrated the high specificity of this biosensor for detecting p 53 mutation.

Compared to the currently available assays for detecting p 53 mutation, this biosensor method has many merits. First, this biosensor has high selectivity and sensitivity, which could be achieved through rigid DNA hybridization on the surface and a unique optical detection scheme based on LSPR. In addition, modified SAM on the surface of a silver nanochip was critical to achieve highly sensitive and selective detection of target DNA, as well as for stabilizing the nanoparticles and preventing non-specific binding. Second, unlike most traditional methods [22], this biosensor does not require an electrophoresis step to differentiate the mutated sequence from the wt sequence. The total analysis time is within $2 \mathrm{~h}$, which is remarkably shorter than that for other current methods. Moreover, the entire detection process could be successfully implemented without any labeling procedure, making it more convenient and rapid, and avoiding signal masking by the label's high background signal. Third, this biosensor is easy to prepare, and does not require highly skilled labor or complicated instrumentation. It could detect very low concentrations of target DNA, using very small sample volumes. Finally, as compared to the commercially-available SPR sensor [23], our newly-developed LSPR biosensor could be implemented using simple, portable, robust, and low-cost equipment. This makes the use of our biosensor particularly well-suited to extensive application in the clinical laboratory.

To date, few of the published studies have aimed to develop a LSPR biosensor for the detection of human gene mutations. Yoo et al. first reported the use of a LSPR-based nanoparticle array chip to detect BIGH3 gene mutations, and provided a new diagnostic tool that allowed selective and sensitive detection of gene mutations implicated in human diseases [26]. Our study is the first example of a LSPR biosensor applied for detection of $\mathrm{p} 53$ gene mutations. However, further optimization and improvement of this biosensor is necessary, including development of a massively parallel detection capability for such a nanochip. In addition, the stability and reproducibility of this sensor also need to be further evaluated in future investigations involving large numbers of samples.

In conclusion, our findings reveal that the newly-developed LSPR biosensor could be used as a novel rapid and sensitive method for detecting p53 gene mutation, and has several advantages over the currently-available techniques. In particular, the rapid label-free detection and low instrumentation cost associated with the LSPR biosensor support its widespread potential clinical applications. Future studies should investigate the applicability of this biosensor for detecting other gene mutations besides the single point mutation in p53 reported in this study.

Acknowledgments: We would like to thank Lai Ting, Gao Ping, and Quan Yi for their contributions to this work. This study was supported by grants from the National Key Basic Research Program of China (No. 2011CB301800) and the Natural Science Foundation of China (No. 60736037).

\section{References}

[1] YONZON CR, STUART DA, ZHANG X, MCFARLAND AD, HAYNES CL et al. Towards advanced chemical and biological 
nanosensors-An overview. Talanta 2005; 67: 438-448. http:// dx.doi.org/10.1016/j.talanta.2005.06.039

[2] ENDO T, KERMAN K, NAGATANI N, HIEP HM, KIM $\mathrm{D}-\mathrm{K}$ et al. Multiple label-free detection of antigen-antibody reaction using localized surface plasmon resonance-based core shell structured nanoparticle layer nanochip. Anal Chem 2006; 78: 6465-6475. http://dx.doi.org/10.1021/ac0608321

[3] CANTALE V, SIMEONE FC, GAMBARI R, RAMPI MA Gold nano-islands on FTO as plasmonic nanostructures for biosensors. Sens Actuators B 2011; 152: 206-213. http://dx.doi. org/10.1016/j.snb.2010.12.008

[4] CHEN Y, MUNECHIKA K, GINGER DS Dependence of fluorescence intensity on the spectral overlap between fluorophores and plasmon resonant single silver nanoparticles. Nano Lett 2007; 7: 690-696. http://dx.doi.org/10.1021/ $\underline{\mathrm{nl} 062795 \mathrm{z}}$

[5] ZHAO J, ZHANG XY, YONZON CR, HAES AJ, VAN DUYNE RP Localized surface plasmon resonance biosensors. Nanomedicine 2006; 2: 219-228. http://dx.doi.org/10.2217/ $\underline{17435889.1 .2 .219}$

[6] JIN R, CAO Y, MIRKIN CA, KELLY KL, SCHATZ GC et al. Photoinduced conversion of silver nanospheres to nanoprisms. Science 2001; 294: 1901-1903. http://dx.doi. org/10.1126/science. 1066541

[7] ANKER JN, HALL WP, LYANDRES O, SHAH NC, ZHAO J et al. Biosensing with plasmonic nanosensors. Nat Mater 2008; 7: 442-453. http://dx.doi.org/10.1038/nmat2162

[8] ZHU SL, LI F, DU CL, FU YQ A localized surface plasmon resonance nanosensor based on rhombic Ag nanoparticle array. Sens Actuators B 2008; 134: 193-198. http://dx.doi. org/10.1016/j.snb.2008.04.028

[9] LAI T, HOU QN, YANG H, LUO XG, XI MR Clinical application of a novel sliver nanoparticles biosensor based on localized surface plasmon resonance for detecting the microalbuminuria. Acta Biochim Biophys Sin 2010; 42: 787-792. http://dx.doi.org/10.1093/abbs/gmq085

[10] HAES AJ, CHANG L, KLEIN WL, VAN DUYNE RP Detection of a biomarker for Alzheimer's disease from synthetic and clinical samples using a nanoscale optical biosensor. J Am Chem Soc 2005; 127: 2264-2271. http://dx.doi.org/10.1021/ja044087q

[11] KREUZER MP, QUIDANT R, SALVADOR JP, MARCO MP, BADENES G Colloidal-based localized surface plasmon resonance (LSPR) biosensor for the quantitative determination of stanozolol. Anal Bioanal Chem 2008; 391: 1813-1820. http://dx.doi.org/10.1007/s00216-008-2022-Z

[12] ENDO T, KERMAN K, NAGATANI N, TAKAMURA Y, TAMIYA E Label free detection of peptide nucleic acid-DNA hybridization using localized surface plasmon resonance based optical biosensor. Anal Chem 2005; 77: 6976-6984. http://dx.doi.org/10.1021/ac0513459

[13] ZHOU WJ, MUGGERUD AA, VU P, DUE E U, SORLIE T et al. Full sequencing of TP53 identifies identical mutations within in situ and invasive components in breast cancer suggesting clonal evolution. Molecular Oncology 2009; 3: 214-219. http://dx.doi.org/10.1016/j.molonc.2009.03.001

[14] HUSSAIN I, REHMAN S, AFROZE D, ZAHOOR L, ABDULLAH S et al. Mutational spectrum of conserved regions of
TP53 and PTEN genes in Kangri cancer (of the skin) in the Kashmiri population. Mutat Res 2009; 676: 5-10.

[15] PAGET V, LECHEVREL M, SICHEL F Acetaldehyde-induced mutational pattern in the tumor suppressor gene TP53 analysed by use of a functional assay, the FASAY (functional analysis of separated alleles in yeast). Mutat Res 2008; 652: 12-19.

[16] HOLMILA R, BORNHOLDT J, SUITIALA T, CYR D, DICTOR M et al. Profile of TP53 gene mutations in sinonasal cancer. Mutation Research 2010; 686: 9-14. http://dx.doi. org/10.1016/j.mrfmmm.2009.12.003

[17] OLIVIER M, HUSSAIN SP, CARON DF, HAINAUT P, HARRIS CC TP53 mutation spectra and load: a tool for generating hypotheses on the etiology of cancer. IARC Sci Publ 2004: 247-270.

[18] ZAINUDDINA N, MURRAYB F, KANDURIB M, GUNNARSSONC R, SMEDBYD KE et al. TP53 Mutations are infrequent in newly diagnosed chronic lymphocytic leukemia. Leukemia Research 2011; 35: 272-274. http://dx.doi. org/10.1016/j.leukres.2010.08.023

[19] BRANTLEY MA, WORLEY JL, HARBOUR JW Altered expression of $\mathrm{rb}$ and $\mathrm{p} 53$ in uveal melanomas following plaque radiotherapy. Am J Ophthalmol 2002; 133: 242-248. http://dx.doi.org/10.1016/S0002-9394(01)01362-9

[20] CHENG L, ZHANG SB Bladder cancer: translating molecular genetic insights into clinical practice. Human Pathology 2011; 42: 455-481. http://dx.doi.org/10.1016/ j.humpath.2010.07.007

[21] JIANG TS, MINUNNI M, MASCINI M Towards fast and inexpensive molecular diagnostic: the case of TP53. Clinica Chimica Acta 2004; 343: 45-60. http://dx.doi.org/10.1016/ j.cccn.2004.01.018

[22] HOLMILA R, HUSGAFVEL-PURSIAINEN K Analysis of TP53 gene mutations in human lung cancer: Comparison of capillary electrophoresis single strand conformation polymorphism assay with denaturing gradient gel electrophoresis and direct sequencing. Cancer Detection and Prevention 2006; 30: 1-6. http://dx.doi.org/10.1016/j.cdp.2005.10.004

[23] JIANG TS, MINUNNI M, WILSON P, ZHANG J, TURNER APF et al. Detection of TP53 mutation using a portable surface plasmon resonance DNA-based biosensor. Biosensors and Bioelectronics 2005; 20: 1939-1945. http://dx.doi.org/10.1016/ j.bios.2004.08.040

[24] SOLER S, RITTORE C, TOUITOU I, PHILIBERT L A comparison of restriction fragment length polymorphism, tetra primer amplification refractory mutation system PCR and unlabeled probe melting analysis for LTA $+252 \mathrm{C}>\mathrm{T}$ SNP genotyping. Clinica Chimica Acta 2011; 412: 430-434. http:// dx.doi.org/10.1016/j.cca.2010.11.012

[25] CHEREPINSKY V, HASHMI G, MISHRA B Competitive hybridization models. Physical Review E 2010; 82: 1-17. http://dx.doi.org/10.1103/PhysRevE.82.051914

[26] YOO SY, KIM DK, PARK TJ, KIM EK, TAMIYA E et al. Detection of the most common corneal dystrophies caused by $\mathrm{BIGH} 3$ gene point mutations using a multispot gold-capped nanoparticle array chip. Anal Chem 2010; 82: 1349-1357. http://dx.doi.org/10.1021/ac902410z 